\title{
$(3)$
SHE EFFECT OF A VARNISH CONTAINING SELF-CURING RESIN ON THE
SOFTESS OF TWO TYPES OF TISSUE CONDITIONERS
}

\section{ABSTRACT}

Objectives: One of the limitations of tissue conditioners (TC) is the gradual hardening of the material in a short time after insertion in the mouth. This study aimed to determine the softness of two different tissue conditioners with and without the coating made up of $1,1,1$ trichloroethan and self-curing acrylic resin.

Materials and Methods: In this experimental study, Acrosoft (Marlic, Tehran, Iran) and GC (GC corporation, Tokyo, Japan) tissue conditioners were examined. 28 discs of $20 \times 3 \mathrm{~mm}$ dimensions were prepared for each tissue conditioner $(n=14)$. Half of the samples in each group were coated with varnish coating made up of 1,1,1 trichloroethan and self-curing acrylic resin. The hardness of all samples was measured at five intervals of 1,3,7,14, and28 days by a Shore-A Durometer with a conical indenter. The data were analyzed by descriptive statistics and Friedman analyses. $\mathrm{P}<0.05$ was considered statistically significant.

Results: The mean hardness of the GC and Acrosoft tissue conditioners on days 1, 3, 7, 14, and 28 in both varnish-coated and non-varnish-coated groups were statistically different and Acrosoft tissue conditioner was harder than the GC. In the paired mean hardness comparison on days 1, 3, 7, 14, and 28 in the GV and G0 groups: this trend was the same in AV and A0 groups. The comparison of hardness in the GV and G0 groups at each time interval indicated that only on day 3, the control group (G0) was harder than the surface coating group (GV). The comparison of the hardness in the AV and A0 groups showed that on days 3 and 7, the hardness in the control group (A0) was higher than the surface coating group (AV).

Conclusions: The varnish containing self-curing resin can soften the Acrosoft and GC tissue conditioner in a short time. Moreover, this varnish can be clinically applied in the borders between the soft liner and acrylic denture, which is usually the starting point for debonding.

Keywords: Denture liner, self-curing resin, tissue conditioning.

\author{
(D) Shima Ghasemi ${ }^{1}$ \\ Katayoun $\mathrm{Sadr}^{1}$ \\ Negar Ghorbani² \\ Mahdieh Esmailzadeh ${ }^{2}$ \\ Elaheh Akhgari ${ }^{3}$ \\ *Amir Reza Babaloo ${ }^{4}$
}

ORCID IDs of the authors:

S.G. $\quad 0000-0003-1557-5096$

K.S. $\quad 0000-0002-9105-2310$

N.G. $\quad 0000-0001-6005-6565$

M.E. $\quad 0000-0002-2718-5995$

E.A. $\quad 0000-0002-1606-0791$

A.R.B. $0000-0002-2535-1232$
Received : :16.03.2020

Accepted : 19.06 .2020

How to Cite: Ghasemi S, Sadr K, Ghorbani N, Esmailzadeh M, Akhgari E, Babaloo AR. The Effect of a Varnish Containing Self-Curing Resin on the Softness of Two Types of Tissue Conditioners. Cumhuriyet Dent J 2020;23:3:167-173.

*Corresponding Author:

Department of Periodontics, Faculty of Dentistry, Tabriz University of Medical Sciences, Tabriz, Iran.

E-mail: amirrezababaloo@yahoo.com 


\section{INTRODUCTION}

Tissue conditioners (TCs) are soft and flexible materials used for the treatment of inflammation, tissue irritation, and functional molding. These materials are commonly used as temporary reline material, in tissue repair stage after implant insertion and in maxillofacial dentures. ${ }^{1}$ Moreover, these materials are used to evenly disperse the forces applied to soft tissues during function; their resilience can absorb force during chewing and allows chewing forces to spread widely over the residual alveolar bone. When mucosal pain is associated with the rigid denture base, the soft lining materials can act as a cushion. ${ }^{2,3}$

Tissue conditioners are composed of a powder and liquid system with a powder containing Poly Methyl methacrylate (PMMA) polymer, a liquid containing ethyl alcohol and an aromatic ester that improves the plasticity of the material. ${ }^{4,5}$ Ideally, for adequate cushioning, a tissue conditioner should be replaced every 3-4 days. ${ }^{5}$ The limiting factor for the use of tissue conditioners is the effect of the oral environment on the physical properties of the substance. The moist environment of the oral cavity dissolves ethanol and ester into saliva and absorbs water in the polymeric phase. ${ }^{4}$ Loss of the plasticity agent causes a gradual hardness of tissue conditioners, properties such as surface integrity and viscoelasticity are affected, and the lifespan of the material is reduced, leading to the loss of functionality in the material. ${ }^{4}$

Loss of surface integrity and the surface porosity gives rise to the microbial biofilm accumulation and pathological reactions. Various strategies have been proposed to prevent biofilm accumulation, such as mixing tissue conditioner with antifungal agents or using a coating material to block the surface porosity of the material. ${ }^{1} \mathrm{Up}$ to now, various materials have been used as surface coatings to coat the surface porosities of tissue conditioner, and various studies have been conducted on the extent of their influence on tissue conditioners. In a study by Casey and Scheer ${ }^{7}$, it was reported that a tissue conditioner with monopoly coating can extend the lifespan of the material by up to 30 days and sometimes up to one year, due to the fact that this coating maintains the flexibility of the material for a long time by protecting the surface material, which restricts the growth of microorganisms.

Deminguez et $a l .^{8}$ found that tissue conditioners coated with monopoly gradually lose their alcohol in the laboratory environment but do not absorb water, thereby maintaining their flexibility and reducing the growth rate of the microorganism.

Gronet's ${ }^{9}$ study showed that the resilience of the tissue conditioner coated with monopoly or Palaseal improved, although different tissue conditioners responded differently to the surface coating. This discrepancy may be due to differences in the adhesion of the surface coating with different tissue conditioners or differences in the components of tissue conditioner such as alcohol or ester percentage. Malmstrom ${ }^{1}$ observed a marked decrease in the rate of surface deterioration and loss of softness by covering the surface of the GC tissue conditioner with monopoly and Palaseal. Another material introduced by Zarb et $a .^{6}$ to block surface porosities and reduce biofilm accumulation on tissue conditioner is the combination of 1,1,1trichloroethane with self-curing resin.

Given that all studies on surface coatings are industrial, no study was found to show that the varnish introduced by Zarb et al. ${ }^{6}$ is desirable in terms of softness and clinical application. On the other hand, studies are conducted on fully laboratory environments and saliva present in the oral environment that results in a difference in the solubility of the material compared to conventional environments. ${ }^{4}$ Therefore, this study investigates the effect of a custom-made varnish introduced by Zarb et al. ${ }^{6}$ on two types of tissue conditioners including GC America and Acrosoft TC (Marlic, Iran) in the medium containing artificial saliva. The reason for using GC America tissue conditioner is its common usage by clinicians and the reason for using Acrosoft Iran is its availability. Therefore, according to the abovementioned descriptions, the purpose of this study was to investigate the effect of a varnish made 
from the combination of self-curing acrylic resin and 1,1,1-trichloroethane solution on the softness of two commercial types of tissue conditioners including GC America and Acrosoft Iran.

\section{MATERIALS AND METHODS}

This study was an experimental interventional study. The study protocol was approved by the Ethics Committee of Research Council of Tabriz Dental School, Tabriz, Iran (approval number: IR.TBZMED.REC.1394.863). All the procedures of the study were performed based on the Declaration of Helsinki.

GC tissue conditioner (GC Corporation, Tokyo, Japan, LOT 1212111) was prepared according to the manufacturer's instructions as 1 unit of powder to 2 units of liquid (LOT 1212111). Thus, $2.4 \mathrm{~g}$ of the powder was taken by the cup and added to $2 \mathrm{ml}$ of the liquid. The resulting mixture was stirred with a spatula for 30-60 seconds to make it homogeneous. Acrosoft tissue conditioner (AcrosoftTC1, Marlic, Tehran, Iran, LOT: UTC1 3135-1) was also added, according to the manufacturer's instructions, as 1 volume of powder (LOT: PTC1 3005-1) (about $2.2 \mathrm{~g}$ ) to 4 units of liquid (LOT: LTC 1 3006) measured by a dropper (about $1.8 \mathrm{~g}$ ) and stirred for 30 seconds with a spatula to make it uniform. After 1-2 minutes of preparation, both types of tissue conditioners were placed on a clean glass slab. After inserting $3 \mathrm{~mm}$ of thick acrylic stops, a second glass slab was applied to the mixture/composition until a thickness of $3 \mathrm{~mm}$ was obtained from each tissue conditioner (Fig 1abc).

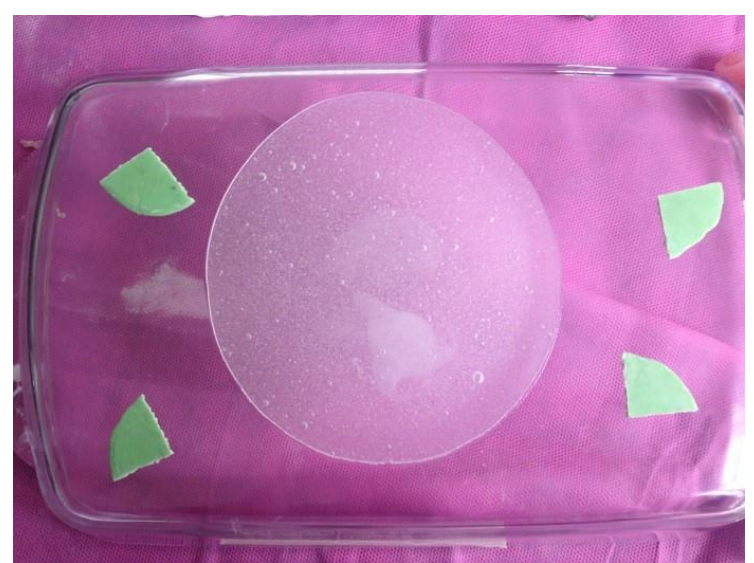

Figure1-a. The GC tissue conditioner located between two glass slabs with green acrylic stops,

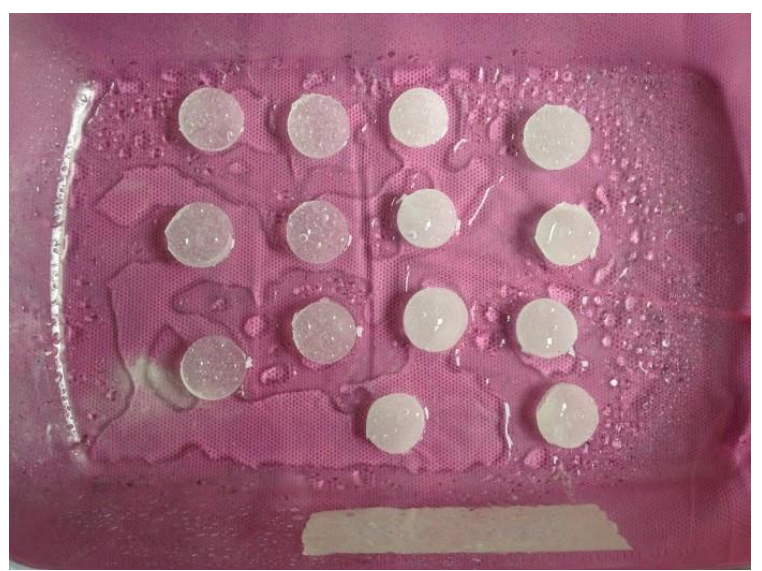

Figure1-b. The Acrosoft tissue conditioner located between two glass slabs with green acrylic stoppers,

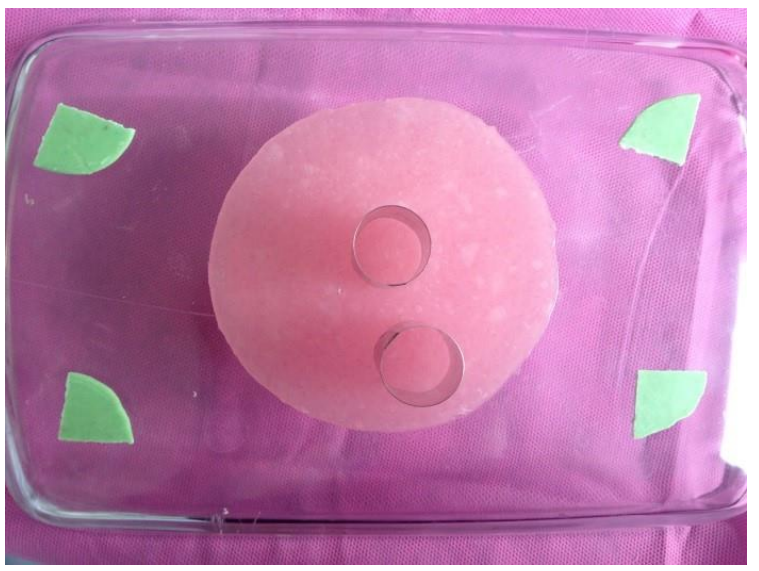

Figure1-c. Discs prepared by a group of tissue conditioners inside artificial saliva solution.

The tissue conditioner was left in the same state for 10-15 minutes to allow the slabs to be separated. Then, with 20-mm-diameter aluminum molds, 28 discs of $20 \times 3 \mathrm{~mm}$ dimensions were prepared for each tissue conditioner.

To prepare the varnish, $50 \mathrm{ml}$ of 1,1,1trichloroethane solution (402877-Sigma-Aldrich, St. Louis, USA) was poured into a closed glass bottle with $3 \mathrm{ml}$ of self-curing acrylic resin powder (Triplex cold Ivoclar Vivadent Inc. USA). The varnish introduced by Zarb et al. ${ }^{6}$ was obtained from the combination of $50 \mathrm{ml}$ of the 1,1,1-trichloroethane solution with $2 \mathrm{ml}$ of acrylic resin powder. Since the resulting compound is required to have glycerin consistency, the powder should be added as needed in case of inadequate viscosity. In this study, we obtained the desired concentration with $3 \mathrm{ml}$ of selfcuring acrylic resin powder. The mixture was kept in a closed glass for 24 hours to dissolve the powder in the liquid completely.

Hardness of all samples was measured at 5 intervals of $1,3,7,14$, and 28 days by a Shore-A 
Durometer (TECLOCK, JIS K 6301A, Osaka, Japan) with a conical indenter. We coated all surfaces of 14 of the 28 discs prepared in each of the two types of GC and Acrosoft tissue conditioner with varnish (Group 1 and Group 2). The impregnation process was performed in three steps (to impregnate all surfaces correctly and completely) with a 5-minute interval using a soft brush. The 14 subsequent discs in both GC and Acrosoft tissue conditioners were not impregnated to the varnish as the control group (Group 3 and Group 4). All 4 groups were housed in separate containers in artificial saliva solutions (Hypozalix: Biocodexinc, Paris, France).

Then, the softness of all samples was measured at 5 intervals of $1,3,7,14$, and 28 days by a ShoreA Durometer (TECLOCK, JIS K 6301A, Osaka, Japan) with a blunt-pointed indenter of $0.8 \mathrm{~mm}$ in diameter which tapers to a cylinder of $1.6 \mathrm{~mm}$ and has an inserted scale (0-100). It was measured by applying a fast and intense pressure to the sample, and recording the largest digit.

\section{Statistical Analysis}

Finally, the data obtained from the study were analyzed by descriptive statistics (percentage, Mean \pm SD) and Friedman analysis in SPSS.17. In this study, p-values of less than 0.05 were considered statistically significant.

\section{RESULTS}

The samples of each study group were tested by Durometer after immersion in artificial saliva at different intervals. Table 1 shows the mean surface hardness score at these different intervals.

- Time impact evaluation:

After Kolmogorov-Smirnov test, due to data abnormality (p-value <0.007), Friedman test was run to compare the hardness of the samples on different days. Friedman test showed a statistically significant difference between the mean hardness of the GC and Acrosoft tissue conditioners on days $1,3,7,14$ and 28 in both varnish-coated and non-varnish-coated groups (pValue < 0.05) (Table 1 and 2, Fig 2 and 3).

Table 1. Mean \pm standard deviation of the hardness of GC tissue conditioner at 5 different time intervals.

\begin{tabular}{|c|c|c|c|c|c|}
\hline group & & Mean & Std. Deviation & Mann-Whitney U Statistic & p-Value \\
\hline Day1 & $\begin{array}{l}\mathrm{G}^{*} \\
\mathrm{GV}^{*}\end{array}$ & $\begin{array}{l}7 \\
8\end{array}$ & $\begin{array}{c}.0 \\
1\end{array}$ & 57 & 0.056 \\
\hline Day3 & $\begin{array}{l}\text { G0 } \\
\text { GV }\end{array}$ & $\begin{array}{l}15 \\
13\end{array}$ & $\begin{array}{c}2.05 \\
1\end{array}$ & 46 & 0.017 \\
\hline Day7 & $\begin{array}{l}\text { G0 } \\
\text { GV }\end{array}$ & $\begin{array}{l}27 \\
38\end{array}$ & $\begin{array}{l}1 \\
1\end{array}$ & 0 & 0.001 \\
\hline Day 14 & $\begin{array}{l}\text { G0 } \\
\text { GV }\end{array}$ & $\begin{array}{l}33 \\
45\end{array}$ & $\begin{array}{l}3 \\
5\end{array}$ & 4 & 0.001 \\
\hline Day28 & $\begin{array}{l}\text { G0 } \\
\text { GV }\end{array}$ & $\begin{array}{l}43 \\
48\end{array}$ & $\begin{array}{l}2 \\
3\end{array}$ & 32 & 0.002 \\
\hline
\end{tabular}

*G0: GC without varnish

$* \mathrm{GV}$ : GC with varnish applied to surface of specimens

Table 2. Mean \pm standard deviation of the hardness of Acrosoft tissue conditioner at 5 different time intervals.

\begin{tabular}{|c|c|c|c|c|c|}
\hline group & & Mean & Std. Deviation & $\begin{array}{c}\text { Mann-Whitney U } \\
\text { Statistic }\end{array}$ & $\mathrm{p}$-Value \\
\hline \multirow{2}{*}{ Day1 } & $\mathrm{A} 0^{*}$ & 10 & .00 & 30 & 0.002 \\
\hline & $\mathrm{AV}^{*}$ & 12 & 1 & & \\
\hline \multirow{2}{*}{ Day3 } & A0 & 25 & 2.04 & 30 & 0.002 \\
\hline & $\mathrm{AV}$ & 23 & 1 & & \\
\hline \multirow{2}{*}{ Day7 } & A0 & 39 & 2 & 37 & 0.005 \\
\hline & AV & 36 & 1 & & \\
\hline \multirow{2}{*}{ Day14 } & A0 & 51 & 4 & 54 & 0.043 \\
\hline & AV & 54 & 3 & & \\
\hline \multirow{2}{*}{ Day28 } & A0 & 55 & 2 & 58 & 0.065 \\
\hline & $\mathrm{AV}$ & 58 & 4 & & \\
\hline
\end{tabular}

*A0: Acrosoft without varnish

*AV: Acrosoft with varnish applied to surface of specimens 


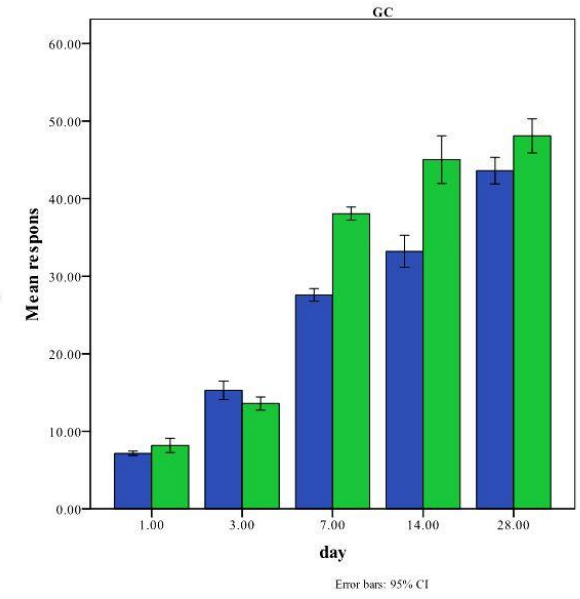

Figure2. The hardness of GC varnish-impregnated and non-varnishimpregnated tissue conditioner containing self-curing resin at 5 different time intervals $(1,3,7,14$, and 28 days).

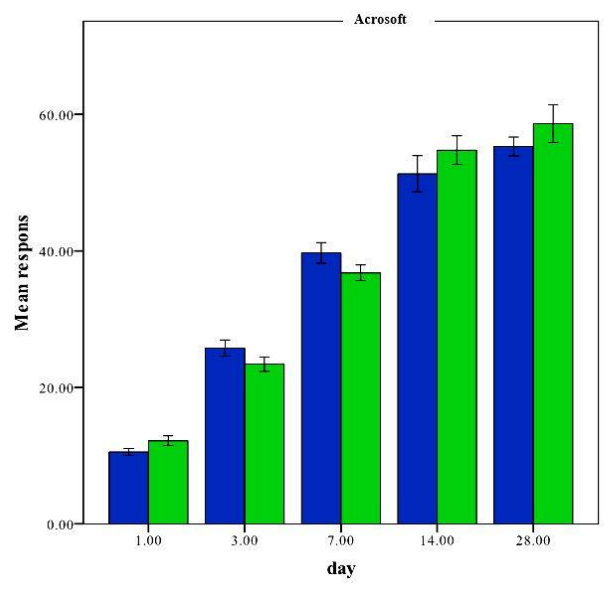

varnish
胞o
yes

Figure3. The hardness of Acrosoft varnish-impregnated and nonvarnish-impregnated tissue conditioner containing self-curing resin at 5 different time intervals $(1,3,7,14$, and 28 days).

In the paired mean hardness comparison on days $1,3,7,14$ and 28 in the GV (Group 1) and G0 (Group 3) groups by Wilcoxon test, a statistically significant difference was observed between all pairs of the groups (p-value $<0.009$ ). There was the highest mean hardness difference on consecutive days at days 3 to 7 (12 units in the G0 group, and 24 units in the GV group). A statistically significant difference was observed in the paired mean hardness comparison on days 1 , $3,7,14$ and 28 in the groups of AV (Group 2) and A0 (Group 4) by Wilcoxon test between in all pairs of the groups (p-value <0.013). The highest mean hardness difference on consecutive days was at days 1 to 3 in the A0 (Group 4) group and days 7 to 14 in the AV (Group 2) group.

- Varnish effect comparison:

The comparison of hardness in the GV (Group 1) and G0 (Group 3) groups at each time interval indicated that there was no significant difference between the two groups only on the first day (p-value $<0.056$ ) and this difference was statistically significant for the remaining days. Only on day 3, the control group had a higher hardness than the surface coating group. The comparison of the hardness in the AV (Group 2) and A0 (Group 4) groups showed that the difference was statistically significant except for day 28 (p-value $=0.065)$. This difference was statistically significant for the rest of the days. On days 3 and 7, the hardness in the control group was higher than the surface coating group (Fig 4).

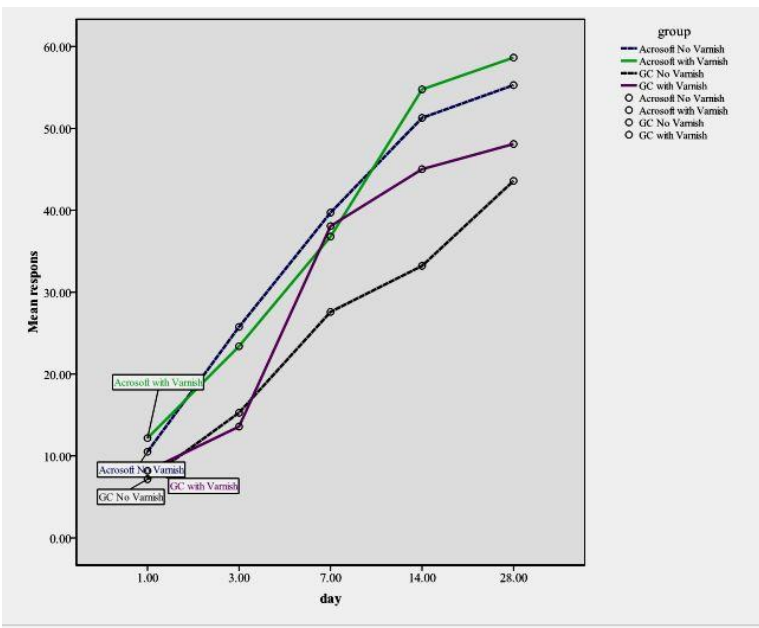

Figure4. Comparison of the hardness of Acrosoft and GC varnishimpregnated tissue conditioner containing self-curing and varnishfree resin at 5 different time intervals $(1,3,7,14$, and 28 days).

\section{DISCUSSION}

Conventional and available tissue conditioners have different clinical applications but are still far from the ideal. ${ }^{10}$ The limitations of these materials are the loss of resilience over time and their susceptibility to surface wear. One way to extend the durability of tissue conditioners is to use surface coatings for maintaining surface integrity and softness and reducing the growth of microorganisms in these materials. ${ }^{4,10}$

The present in vitro study was conducted on the effect of applying a custom-made varnish (combining 1,1,1-trichloroethane with self-curing acrylic resin) on the hardness of two commercial types of tissue conditioner including Acrosoft and GC over a 28-day period (days 1, 3, 7, 14, 28) after mixing. The results showed that the hardness of all samples (with or without varnish) increased with time. Although in both commercial types of tissue conditioner, the varnished group had a higher hardness than the corresponding control 
group on the first day, varnish-coated groups showed less hardness than the control groups on the third day. In the Acrosoft group, even on the seventh day, the varnished group was softer than the control group. However, this trend was reversed in the next few days and the presence of varnish on the specimens made them harder (compared to the control group). In general, an increase in hardness may be associated with the loss of alcohol and/or plasticizer. ${ }^{11}$ Ethanol is the main substance released on the first day and its loss is a major factor in increasing hardness. ${ }^{12,13} \mathrm{It}$ can be stated that on the first day, varnish forms a relatively hard layer on the samples which increases the sample hardness, but partially inhibits the release of alcohol and plasticizer and delays the hardness of tissue conditioner by a few days. After one week, the hardness in the varnished group increased significantly, indicating that the varnish has no effect on the softness of tissue conditioner in the long run.

The finding that varnish makes tissue conditioner harder in the long run (more than 14 days) is consistent with the reports presented by Ebadian $^{4}$ who investigated the impact of Monopoly varnish application on the hardness of Acrosoft and Viscogel tissue conditioners. In the study by Ebadian ${ }^{4}$, the varnished groups had higher hardness at all-time intervals, whereas in the present study, the varnished samples had less hardness than the control group in the first 3 days. The difference may be due to the differences in the type of surface coating varnish that may affect the rate of alcohol loss and plasticizer or the structure of the material.

Malmstrom $^{1}$ investigated the effect of Monopoly and Permaseal coatings on the softness of GC tissue conditioner in the oral environment. His results showed that both types of coatings keep the tissue conditioner soft for more than a month. The difference in results is not unexpected as the study environment and the type of varnish are different and, according to the reports, being in vivo or in vitro affect the results and the loss of ethanol and plasticizer is not the same in vivo and in vitro conditions. ${ }^{11}$
The results also showed that, in general, Acrosoft tissue conditioner was harder than the GC and only on day 7 after mixing, and the mean hardness in the varnished GC group was slightly higher than that in the varnished Acrosoft group. Therefore, the type of tissue conditioner has a significant effect on softness and its maintenance over time. Murata ${ }^{14}$ recommended that since materials have a wide range of viscoelastic properties, the appropriate commercial type should be selected according to their clinical application, the intended case, and the expected softness.

According to these studies and the present study, the effect of varnish application on the softness of tissue conditioners is largely dependent on the type of tissue conditioners, the type of varnish, and the time elapsed after mixing. Within the scope of the study, the varnish introduced in this research can soften the tissue conditioner within a 3- to 7-day interval, after which the material hardens more rapidly. Certainly, when the softness of tissue conditioner is of the utmost importance, replacement of the whole material is preferable to varnish application, but this varnish may be useful in the borders of the coating surface of tissue conditioner, where dryness and abrasion are more common. Since applying varnish to the whole tissue conditioner surface extends the service life only for a short time, it is best to apply this varnish on the old soft liner in the border areas to make it softer for a while.

\section{CONCLUSIONS}

By the passage of time, the tissue conditioners become progressively harder, but the GC tissue conditioner is still softer than the Acrosoft tissue conditioner. In addition, the application of varnish over 3 days made tissue conditioners softer and in both groups, the varnish made tissue conditioners harder after 7 days.

The varnish containing self-curing resin can be clinically applied in the borders between the soft liner and acrylic denture, which is usually the starting point for debonding. It is available in every dental office and user-friendly. It is costeffective for the patient by reducing the frequency 
of dental visits for soft liner replacements and decreasing the chairside time for the dentist.

\section{ACKNOWLEDGMENT}

The authors would like to acknowledge the Dental and Periodontal Research Center at Tabriz University of Medical Sciences for the financial support of this project.

\section{CONFLICTS OF INTEREST STATEMENT}

The authors declare no conflicts of interest.

\section{REFERENCES}

1. Malmström HS, Mehta N, Sanchez R, Moss ME. The effect of two different coatings on the surface integrity and softness of a tissue conditioner. J Prosthet Dent 2002;87:153-157.

2. Akin H, Tugut F, Mutaf B, Guney U, Ozdemir AK. Effect of sandblasting with different size of aluminum oxide particles on tensile bond strength of resilient liner to denture base. Cumhuriyet Dent J 2011;14:5-11.

3. Soygun K, BOLAYIR G, Kapdan A. Ozone gas effect on tensile bond strength between soft liner and PMMA. Cumhuriyet Dent J 2014;17(3):215-222.

4. Ebadian B, Navarchian AH, Sedighipour L. The Effect of surface coating on softness of two kind of tissue conditioners. Dent Res J 2006;13:8-14.

5. Hayakawa I, Takahashi Y, Morizawa M, Kobayashi S, Nagao M. The Effect of a Fluorinated Copolymer Coating Agent on Tissue Conditioners. Int J Prosthodont 1997;10:44-48.

6. Fenton $\mathrm{AH}$, Chang $\mathrm{T}$. The try-in appointment. In: Zarb GA, Bolender CL, Eckert S, Jacob R, MericskeStern R. Prosthodontic treatment for edentulous patients: complete dentures and implant-supported prostheses. St Louis: Mosby. 2013:379-380.

7. Casey DM, Scheer EC. Surface treatment of a temporary soft liner for increased longevity. J Prosthet Dent 1993;69:318-324.

8. Dominguez NF, Thomas CJ, Gerzina TM. Tissue conditioners protected by a poly (methyl methacrylate) coating. Int J Prosthodont 1996;9:137-141.

9. Gronet PM, Driscoll CF, Hondrum SO. Resiliency of surface-sealed temporary soft denture liners. J Prosthet Dent 1997;77:370-374.

10. Singh K, Chand P, Singh BP, Patel CB. Study of the effect of surface treatment on the long term effectiveness of tissue conditioner. J Oral Sci 2010;52:261-265.

11. Graham BS, Jones D, Sutow E. An in vivo and in vitro study of the loss of plasticizer from soft polymergel materials. J Dent Res 1991;70:870-873.

12. Hong G ,Maeda T, Li Y, Sadamori S, Hamada T, Murata H. Effect of PMMA polymer on the dynamic viscoelasticity and plasticizer leachability of PEMAbased tissue conditioners. Dent Mater J 2010;29:374380.

13. Hong G, Maeda T, Murata H, Sasaki K. The dynamic viscoelasticity and plasticizer leachability of tissue conditioners. Gerodontology 2012;29:284-291.

14. Murata H, Taguchi N, Hamada T, McCabe JF. Dynamic viscoelastic properties and the age changes of long-term soft denture liners. Biomaterials 2000;21:1421-1427. 